\title{
Observations and Conversations: Home Preparation of Infant Formula Among a Sample of Low-Income Mothers in the Southeastern US
}

\author{
Rebecca G. Ellison, MS-MPH, RDN ${ }^{1}$; Betty P. Greer, PhD, RDN²; Janie L. Burney, PhD, RDN²; \\ L. Suzie Goodell, PhD, RDN ${ }^{3}$; Katherine B. Bower, PhD, MPH, RDN ; \\ Jennifer C. Nicklas, MS-MPH, RDN ${ }^{5}$; Zixin Lou, PhD ${ }^{4}$; Katherine F. Kavanagh, PhD, RDN ${ }^{4}$
}

\begin{abstract}
Objective: Explore infant formula preparation attitudes and beliefs among low-income, formulafeeding, Southeastern US mothers.

Design: Cross-sectional study using in-home observations and in-depth interviews.

Setting: Participant homes.

Participants: Thirteen low-income mothers of normal birth weight, healthy, term infants aged $\leq 3$ months, who were predominantly feeding powdered or from-concentrate formula.

Variables Measured: Reading formula preparation instructions; order of added ingredients; leveling powdered formula scoop(s); adding cereal or other ingredients to bottles.

Phenomenon of Interest: Perceptions of formula preparation or manipulation.

Analysis: Descriptive statistics described sample characteristics and home observation variables. Thematic analysis of in-depth interviews revealed the following major themes: formula preparation can be intimidating; expressions of complex heuristic perceptions about formula preparation; cost and convenience motivate maternal behaviors; and infant cues override recommendations. Data from qualitative and quantitative activities were triangulated.

Results: Behaviors, including improper reconstitution and modifications/additions to prepared formula (eg, infant cereal) were observed during home observations and/or described during in-depth interviews. Inconsistencies were detected between observed behaviors (eg, adding too much water to the bottle) and those reported during in-depth interviews (eg, stating over-dilution could be detrimental to the infant's health). Conclusions and Implications: Targeting knowledge or skills gaps and behavioral motivators in the formula-feeding population could positively affect infant-feeding practices that occur outside of recommendations.
\end{abstract}

Key Words: infant formula, maternal behaviors, infant feeding, motivators, attitudes, WIC (J Nutr Educ Behav. 2017;49:579-587.)

Accepted April 28, 2017.

Data presented in the latest Centers for Disease Control and Prevention Breastfeeding Report Card, representing US births in 2013, indicated that several of the Healthy People (HP) 2020 Breastfeeding Objectives were close to being

\footnotetext{
${ }^{1}$ Knox County Health Department, Knoxville, TN

${ }^{2}$ Department of Family and Consumer Sciences, University of Tennessee Institute of Agriculture, Knoxville, TN

${ }^{3}$ Department of Food, Bioprocessing, and Nutrition Sciences, North Carolina State University, Raleigh, NC

${ }^{4}$ Department of Nutrition, University of Tennessee, Knoxville, TN

${ }^{5}$ Louisiana Department of Education, Baton Rouge, LA

Conflict of Interest Disclosure: The authors' conflict of interest disclosures can be found online with this article on www.jneb.org.

Address for correspondence: Katherine F. Kavanagh, PhD, RDN, Department of Nutrition, University of Tennessee, Knoxville, 1215 W. Cumberland Ave, Knoxville, TN 37996-1920; Phone: (865) 974-6250; Fax: (865) 974-3491; E-mail: kkavanag@utk.edu

(C)2017 Society for Nutrition Education and Behavior. Published by Elsevier, Inc. All rights reserved.

http://dx.doi.org/10.1016/j.jneb.2017.04.027
}

met at the national level. ${ }^{1}$ For example, $81.1 \%$ of US infants were offered the breast at least once, approaching the objective of $81.9 \%$, and exclusivity rates at 3 and 6 months were also approaching the relevant objectives $(44.4 \%$ vs $46.2 \%$ and $22.3 \%$ vs $25.5 \%$ at 3 and 6 months, respectively). Although encouraging, breastfeeding rates continue to be lower among certain populations, such as among low-income women ${ }^{2}$ and women residing in the Southeastern US. $^{3}$ Infants who are not breastfed, exclusively or at all, will receive at least some infant formula ${ }^{4}$ and many will receive it as the predominant or only form of nutrition for the first few months of life. ${ }^{1,5}$ The Special Supplemental Nutrition Program for Women, Infants, and Children (WIC), a federal supplemental food 
program, annually serves over half the US infant population. ${ }^{6}$ Although it provides important support for breastfeeding mothers, ${ }^{7}$ WIC accounts for over half the infant formula purchased in the US annually. ${ }^{8}$ Therefore, it is clear that a large proportion of infants will receive at least some infant formula. Despite this large proportion receiving formula, relatively little research has focused on understanding behaviors and attitudes regarding the proper preparation and feeding of infant formula in populations of healthy infants. ${ }^{4,9-12}$ In the absence of specific medical conditions, improper reconstitution of powdered infant formula (over- or under-dilution) and the addition of infant cereal to bottles of prepared formula are not recommended. ${ }^{13}$ However, previous research indicated that overand under-dilution of reconstituted infant formula ${ }^{9,10,14}$ and the addition of infant cereal to prepared formula ${ }^{11,12,15}$ are occurring and may be of specific concern in low-income populations. ${ }^{14-16}$ These behaviors may be partially explained by a lack of knowledge or understanding of proper preparation, as Lakshman and colleagues ${ }^{10}$ highlighted in a 2009 review of qualitative and quantitative studies conducted with bottle-feeding mothers. In this study, mothers who formula-fed, either by choice or necessity, reported receiving limited education regarding proper preparation. To the best of the authors' knowledge, no work has been completed that combines observations of bottle preparation with in-depth interviews regarding attitudes and beliefs about infant formula preparation. Therefore, the objective was both to observe infant formula preparation and to explore attitudes and beliefs about formula preparation among low-income, formula-feeding mothers of infants aged $\leq 3$ months.

\section{METHODS}

In this cross-sectional study, the researchers completed home observations of infant formula preparation and oneon-one, in-depth interviews assessing maternal attitudes and beliefs related to infant-feeding practices.

\section{Recruitment}

Mothers of normal birth weight, healthy, term infants aged $\leq 3$ months, who were predominantly formula feeding (ie, breastfeeding twice per day or less), using powdered or from-concentrate formula, and who were income-eligible for WIC ( $\leq 185 \%$ of the federal poverty level $)^{17}$ could participate. Recruitment occurred via community health organizations and social media. Study activities were explained via telephone for those who were determined to be eligible based on an online or phone screen; if respondents were interested in participating, home visits were scheduled. Informed consent was obtained verbally over the phone before home visits and written consent was obtained before commencement of study activities during the visit. This study was approved by the University of Tennessee's Institutional Review Board before implementation. Recruitment occurred in the Southeastern US from August, 2012 to April, 2013.

\section{Tools and Training}

A checklist for the home observation (Figure 1) and a semistructured interview guide (Figure 2) were developed by members of the research team with expertise in food safety (JLB), infant formula preparation (JCN, JLB, and KFK), infant-feeding practices (BPG, KBB, KFK, JCN, and RGE), home observation research techniques (LSG), and qualitative methods (LSG and KFK) and were further informed by pilot work conducted with this population. The infant formula preparation checklist (Figure 1) assessed observed behaviors such as hand washing, use of appropriate measuring techniques, and use of the correct formula-to-water ratios (generally 2 $\mathrm{oz}$ of water for every level scoop of powder). The semistructured interview guide (Figure 2 ) assessed maternal attitudes and beliefs related to infantfeeding practices, incorporating openended questions designed to provide scaffolding for conversations about important concepts of interest while allowing for deeper exploration when relevant. ${ }^{18}$ Questions targeted the process of formula preparation, timing of solid food introduction, addition of infant cereal to bottles, infant cues, and sources of trusted infant-feeding information. LSG trained research assistants (RAs) in appropriate home observation and interviewing techniques by using these tools to complete role-playing activities before attending home visits. Training in qualitative methods (KFK) were also provided.

\section{Data Collection}

Observation of bottle preparation was completed first, followed by the interview. Two RAs attended each home visit. During the observation, mothers were asked to prepare at least 2 bottles. The first was prepared using the mother's own formula and equipment (typical bottle) to assess usual preparation. Before the home visit, mothers were asked about the current brand and type of formula they were using, which allowed RAs to bring a different formula for preparation of the second bottle (unfamiliar bottle). The purpose of the unfamiliar bottle was to observe whether mothers reviewed canister information when presented with a novel brand or type of formula and whether preparation differed from the typical bottle. This was important because preparation instructions may differ slightly by formula brand or type. After preparing the unfamiliar bottle, mothers were asked whether they ever prepared a bottle differently from the way in which they prepared their typical bottle. If so, they were asked to prepare a third bottle (alternative bottle) to demonstrate this difference. Using the checklist (Figure 1), RAs independently observed and documented relevant behaviors. Germane observations not captured by the checklist, such as the state of the formula preparation environment, were recorded in the notes section. After each observation, an in-depth, audio-recorded interview was conducted using the semistructured interview guide (Figure 2). Interviewers were encouraged to follow the guide, but to probe further as appropriate. One RA served as interviewer and 1 served as a note taker. At the end of the home visit mothers were provided with information regarding proper preparation of infant formula.

\section{Data Analysis}

Field notes were completed immediately after the home visit. The RAs compared checklists, resolved discrepancies, and created a final master copy of the checklist. This master copy was 


\begin{tabular}{|c|c|c|c|c|c|c|}
\hline \multirow[b]{2}{*}{ Environment } & \multicolumn{5}{|c|}{ Checklist } & Notes \\
\hline & $\begin{array}{l}\text { 1. Location: } \\
\text { 2. Distractions: } \square \mathrm{TV} \\
\text { 3. Other people present: } \\
\text { 4. Supplies from other room }\end{array}$ & $\begin{array}{l}\square \text { Living Roo } \\
\square \text { Radio } \\
\text { : }\end{array}$ & $\begin{array}{l}\mathrm{m} \\
\square \text { No } \\
\square \text { No }\end{array}$ & $\begin{array}{l}\text { Kitchen } \\
\square \text { Phone } \\
\square \text { Yes (note) } \\
\square \text { Yes (note) }\end{array}$ & $\begin{array}{ll}\square \text { Bedroom } & \text { GOther (note) } \\
\square \text { Computer } & \square \text { People } \square \text { None }\end{array}$ & \\
\hline $\begin{array}{l}\text { Sanitation \& } \\
\text { Sterilization }\end{array}$ & $\begin{array}{l}\text { 1. Washed hands with soap } \\
\text { 2. Bottle equipment inspect } \\
\text { 3. Bottle washed with soap } \\
\quad \text { a. If sponge/bottle bi } \\
\text { 4. Source of water: } \square \text { Tap } \\
\text { 5. Water boiled: } \\
\text { 6. Bottle warmed: }\end{array}$ & $\begin{array}{l}\text { and water: } \\
\text { ed: } \\
\text { and water: } \\
\text { rush used, disin } \\
\qquad \text { Filte }\end{array}$ & fected: & $\begin{array}{l}\square \text { No } \square \text { Yes } \\
\square \text { No } \square \text { Yes } \\
\square \text { No } \square \text { Yes } \\
\square \text { No } \square \text { Yes } \\
\square \text { Bottled } \\
\square \text { No } \square \text { Yes } \\
\square \text { No } \square \text { Yes }\end{array}$ & $\begin{array}{l}\square \text { Not Observed } \\
\square \text { Not Observed } \\
\square \text { Not Observed } \\
\square \text { N/A } \\
\square \text { Sterile baby water } \square \text { Other (note) }\end{array}$ & \\
\hline Formula Prep & $\begin{array}{l}\text { 1. In bottle first: } \\
\text { 2. Amount of water: } \\
\text { a. Water leveled: } \\
\text { 3. Scoop from can used: } \\
\text { a. \# of scoops: } \\
\text { b. Formula scoop: } \\
\text { c. Formula leveled: } \\
\text { 4. Cereal in bottle: } \\
\text { 5. Other additions to bottle: } \\
\text { 6. Shakes bottle: } \\
\text { a. How long: } \\
\text { 7. More formula added: } \\
\text { 8. More water added: }\end{array}$ & $\begin{array}{l}\square \text { Water } \\
\overline{\text { oz }}{ }^{\text {at surface }} \\
\square \text { No (note) } \\
\overline{\square \text { Level }} \\
\square \text { Against can } \\
\square \text { No } \square \text { Yes } \\
\square \text { No } \square \text { Yes } \\
\square \text { No } \square \text { Yes } \\
\square \text { No } \square \text { Yes }\end{array}$ & $\begin{array}{l}\text { पForr } \\
\square \text { At e } \\
\square \text { Yes } \\
\end{array}$ & $\begin{array}{l}\text { yula level } \square \text { Quic. } \\
\text { पUnleveled } \\
\square \text { Tapped }\end{array}$ & kly eyed $\quad \square$ Already in bottle & \\
\hline
\end{tabular}

Figure 1. Infant formula preparation checklist used in home observations conducted among low-income, formula-feeding mothers.

coded and double-entered into an electronic spreadsheet for verification, and descriptive statistics were conducted. Trained RAs transcribed audio recordings verbatim using a transcription software program (InqScribe, Chicago, IL) and mothers' names were replaced with pseudonyms. Theoretical thematic analysis was conducted using the process outlined by Clarke and Braun. ${ }^{19}$ Four research team members (RGE, JCN, KBB, and KFK) independently read and memoed the first 3 transcripts, keeping in mind the theoretical constructs related to preparation and feeding of infant formula. These team members then met and discussed their memoing and general impressions. Then a general coding framework was systematically developed and used to code meaningful statements in these and the remainder of the transcripts (with a team meeting held to discuss every 3 transcripts). Memoing continued during this time, allowing for additional codes to develop. An additional researcher joined this process toward the middle of data collection, and 3 original researchers participated fully in most or all team discussions. Before each meeting, team members independently coded and memoed the 3 transcripts. Codes were discussed, compared, and revised by group consensus during each meeting. By the 10th transcript it was determined by group consensus that no new codes had emerged (ie, saturation had been reached). Three additional interviews were completed to verify this assumption. Team review again confirmed that saturation had been reached, because no new codes emerged from these interviews. Team members independently organized codes into general concepts and then met to discuss concepts and organize them into agreedupon overarching themes. As suggested by Clarke and Braun, 1 researcher returned to the data, reviewing each transcript to confirm support of themes by the codes. ${ }^{19}$ She selected meaningful statements, representing the identified themes, and then developed a narrative, comparing themes and observations. It was determined that developing stories, or vignettes, would be the most accessible way to contextualize these findings. Using each mother's transcript and data from the home observation, individual vignettes were drafted using selected quotations to illustrate identified themes (when present) and linking these with the observation data when relevant. Vignettes from mothers whose data provided quotations supporting most or all of the identified themes were selected for inclusion in this report.

\section{RESULTS}

On average, mothers were in their mid20s and predominantly unmarried, and had infants approximately aged 2 months (Table 1). The majority reported being white or Caucasian and/or having $>1$ child; about half reported breastfeeding at least once and about half had completed some college.

\section{Home Observation of Bottle Preparation}

Most mothers (12 of 13) prepared the typical bottle (Table 2) and all used powdered infant formula. One mother did not prepare her typical bottle because she did not have her usual formula available at the time of the home visit. All mothers prepared the second, or unfamiliar bottle. Only 1 mother was 


\begin{tabular}{|c|c|}
\hline Question & Intent of question \\
\hline $\begin{array}{l}\text { Question 1: Think back to the very first time you remember making a } \\
\text { bottle. It may have been for your baby or someone else's baby. Please tell } \\
\text { me how you learned to make a bottle. }\end{array}$ & $\begin{array}{l}\text { How participants learned to make a bottle and a sense } \\
\text { of how much they believe really needs to be learned } \\
\text { about making a bottle (e.g., was it taken seriously). } \\
\text { Did the learning occur in a formal or an informal } \\
\text { setting? Can participants pinpoint a specific event or } \\
\text { was it just something "they have always known?") }\end{array}$ \\
\hline $\begin{array}{l}\text { Question 2. Think about how you normally make a bottle. When might } \\
\text { you make a bottle differently? }\end{array}$ & $\begin{array}{l}\text { Are participants likely to modify bottles? Do they } \\
\text { seem open to it? (Questions } 4 \text { and } 7 \text { explore how they } \\
\text { may rationalize changing/modifying contents.) }\end{array}$ \\
\hline $\begin{array}{l}\text { Question 3. We know that some moms add extra water or less water to } \\
\text { their formula. Tell me about what happens to a baby when EXTRA water } \\
\text { IS ADDED to the formula? Tell me about what happens to a baby when } \\
\text { LESS water IS ADDED to the formula? }\end{array}$ & $\begin{array}{l}\text { How accepting are participants to the idea of } \\
\text { manipulating bottle contents? Does improper dilution } \\
\text { appear to be of concern or is it considered relatively } \\
\text { harmless? If there is concern, do the participants have } \\
\text { an understanding of why? }\end{array}$ \\
\hline $\begin{array}{l}\text { Question 4. Sometimes different situations come up and moms need to } \\
\text { switch their babies' formula. When do you think a mom would need to } \\
\text { change formulas? }\end{array}$ & $\begin{array}{l}\text { Do participants perceive that there are differences in } \\
\text { infant formulas and/or do infant symptoms lead them } \\
\text { to change formula? If there are symptoms that cause } \\
\text { them to change formula, what are they and what } \\
\text { process do they go through when deciding what the } \\
\text { next formula will be? Does changing formula lead to } \\
\text { a resolution? (Hypothesis-generating and very open- } \\
\text { ended). }\end{array}$ \\
\hline $\begin{array}{l}\text { Question 5. Some moms say that formula isn't enough for their young } \\
\text { babies. Some moms say it is enough. Can you tell me what you think } \\
\text { about this? }\end{array}$ & $\begin{array}{l}\text { Targets the perception and understanding of } \\
\text { physiology. In other words, is fluid perceived as 'less } \\
\text { filling' than solid food? Is the formula ever } \\
\text { manipulated in response to infant growth and/or other } \\
\text { infant behaviors like fussiness, etc.? Is the frequency } \\
\text { and/or volume changed? }\end{array}$ \\
\hline $\begin{array}{l}\text { Question 6. We know moms have lots of choices about the bottles and } \\
\text { nipples they use to feed their babies. Please tell me about the kind or } \\
\text { kinds of bottle you use; How about the kind of nipples you use? Please tell } \\
\text { me about that. Sometimes moms decide to use a different nipple. When do } \\
\text { you think a mom would do that? }\end{array}$ & $\begin{array}{l}\text { This targets how flexible participants are in their } \\
\text { behaviors and choices. Do they seek out ways to } \\
\text { control how infants get bottle contents? }\end{array}$ \\
\hline
\end{tabular}

Figure 2. Semistructured interview guide used during home observation among low-income, formula-feeding mothers of infants aged $\leq 3$ months. 


\begin{tabular}{|c|c|}
\hline $\begin{array}{l}\text { Question 7. We know moms who put cereal in their baby's bottle do so for } \\
\text { many different reasons. We've tried to make formula with cereal in the } \\
\text { bottle and even used different nipples, but we couldn't figure out how to } \\
\text { get the formula out of the bottle because it is so much thicker. Can you } \\
\text { tell me how that works? }\end{array}$ & $\begin{array}{l}\text { Targets how modifications, if they are made, might } \\
\text { actually be occurring. }\end{array}$ \\
\hline $\begin{array}{l}\text { Question 8. Please think about a normal day with your baby and when } \\
\text { you make formula bottles. Every mom is different - some make a big } \\
\text { batch of formula for the whole day, some make one bottle at a time right } \\
\text { before their baby is ready to eat. Please describe when you would start } \\
\text { making a formula bottle. Please tell me about your feeding schedule, if } \\
\text { you have one. How does the amount you feed your baby change? }\end{array}$ & Targets general participant feeding patterns. \\
\hline $\begin{array}{l}\text { Question 9. What are some reasons that moms might start to give their } \\
\text { babies solid food? }\end{array}$ & $\begin{array}{l}\text { Further explores motivations to follow, or not follow, } \\
\text { infant-feeding recommendations. }\end{array}$ \\
\hline $\begin{array}{l}\text { Question 10. When it comes to feeding your baby, what do you know now } \\
\text { that you wish you knew when your baby was first born? When it comes to } \\
\text { feeding a baby, what advice would you give to a new mom? When it } \\
\text { comes to feeding your baby, what's the best advice you've received? When } \\
\text { it comes to feeding your baby, what's the worst advice you've received? }\end{array}$ & $\begin{array}{l}\text { Targets the level of valuation of advice from friends, } \\
\text { family, doctors, etc. }\end{array}$ \\
\hline
\end{tabular}

Figure 2. (continued).

Table 1. Demographic Characteristics of a Sample of Low-Income, FormulaFeeding Mothers With Infants Aged $\leq 3 \mathrm{Mo}(\mathrm{n}=13)$

\begin{tabular}{lc} 
& Mean \pm SD \\
Variable & or \% (n) \\
Maternal age, y & $27 \pm 7.6$ \\
Infant age, mo & $1.9 \pm 0.83$ \\
Infant birth weight, g & $3,240 \pm 372.5$ \\
Infant gender (male) & $31(4)$ \\
Marital status (single) & $62(8)$ \\
Parity (multiparous) & $69(9)$ \\
Breastfeeding & $54(7)$ \\
$\quad$ initiation (yes) & $62(8)$ \\
Maternal race & \\
$\quad$ White/Caucasian) & \\
Maternal education & $46(6)$ \\
$\quad$ (Some college/ & \\
college) & \\
Maternal employment & $31(4)$ \\
$\quad$ (Employed) & \\
\hline
\end{tabular}

asked to prepare the third, or alternative bottle. When preparing the typical bottle, 9 mothers were observed to add water and then formula correctly, and 7 leveled the scoop of powdered formula. However, the remaining mothers were observed not to level the formula scoop $(\mathrm{n}=5)$ and to add infant cereal $(\mathrm{n}=3)$, more water after preparation $(\mathrm{n}=2)$, and/or corn syrup $(\mathrm{n}=1)$. When preparing the unfamiliar bottle, 6 mothers reviewed the formula canister instructions before, 9 correctly added water before formula, and 9 leveled the formula scoop. During the observation, 1 mother stated intentionally over-diluting the unfamiliar bottle, which allowed her to assess her infant's liking before preparing it to the recommended strength. Two mothers were observed adding infant cereal to the unfamiliar bottle. The 1 alternative bottle observed was reported to be different from the mother's typical bottle, in that she added infant cereal. The amount of infant cereal added to all 3 bottle types varied; sometimes it was added before and sometimes after the formula powder. No washing of hands or equipment before bottle preparation was observed during the home visit. Bottle preparation was observed in the kitchen, living room, bathroom, and bedroom, and a porch area.

\section{Themes Emerging From In-depth Interviews}

Four major themes emerged from the interviews.

Theme 1: Formula preparation can be intimidating (T1). Mothers reported learning to prepare formula on their own or by observing others, remembered feeling anxious when doing so for the first time, and some reported feeling uncomfortable admitting any confusion. 
Table 2. Results of Home Observations of Bottles of Infant Formula Prepared by Low-Income, Formula-Feeding Mothers $(n=13)$

\section{Bottle Type}

\section{Variable}

Adhered to recommended guidance Reviewed formula canister information Added water before powdered formula Leveled formula in scoop

Did not adhere to recommended guidance Added infant cereal to bottle Added other ingredients to bottle

$\begin{array}{ccc}\begin{array}{c}\text { Typical } \\ (\mathbf{n}=\mathbf{1 2})\end{array} & \begin{array}{c}\text { Unfamiliar } \\ (\mathbf{n}=\mathbf{1 3})\end{array} & \begin{array}{c}\text { Alternative } \\ (\mathbf{n}=\mathbf{1})\end{array} \\ 0 & 6 & 0 \\ 9 & 9 & 0 \\ 7 & 9 & 1 \\ 3 & 2 & 1 \\ 1^{\mathrm{a}} & 0 & 0\end{array}$

${ }^{a}$ Added corn syrup because participant reported having been directed to do so by her pediatrician to alleviate infant constipation.

Notes: Typical bottle was made as per usual, with mother's own supplies; unfamiliar bottle was made with researcher-provided supplies; for the alternative bottle, mothers were requested to make an additional bottle, if reporting sometimes making bottles differently from the typical bottle, to demonstrate this difference.

Theme 2: Mothers expressed complex heuristic perceptions (T2). Mothers communicated complex ideas about the importance of a proper water-toformula ratio, the appropriateness of modifications to bottle contents, and potential outcomes of such modifications. Often this complexity was revealed during analysis, when evaluating the observation data along with the interview transcript.

Theme 3: Cost and convenience motivate maternal behaviors (T3). Mothers reported feeding behaviors that often were motivated by a desire to reduce cost and/or modify infant behaviors in a way that would address their own need for convenience. Although sometimes said to be recommended by doctors, the predominant reported (and sometimes observed) behavior was the addition of infant cereal to bottles, because this was thought to reduce spitting-up and/or increase infant fullness, time between bottles, and sleep duration.

Theme 4: Infant cues override recommendations (T4). Mothers displayed a range of adherence to infant-feeding recommendations, with any intentional lack of adherence often explained by the perception that specific recommendations did not always apply to their infant.

Five vignettes, representative of the complexity of the formula-feeding expe- rience in this sample of mothers, with supporting quotations for at least 3 of the 4 themes, are presented.

Vignette 1: Megan, 36 years old, with a 3-month-old infant and 5 older children. In the home observation she appeared to reconstitute the formula properly (adding water, then leveling the powdered formula scoop), but then added infant cereal and explained that this was a doctor-recommended modification. Megan reported having been nervous when learning to prepare formula for her first child (18 years earlier), stating.

... I was a little nervous because I was afraid, uh, the scoop was a little too much or not enough. 'Cause leveling it, sometimes you worry it's a little too high or too low ... (T1)

However, she went on to say "... It got easier. I got more comfortable ..." Megan indicated that she believed formula was enough for infants, stating.

... It's [formula] got all their nutrition. It ... really does. ... I've even asked ... if she needed vitamins and ... her pediatrician says ' $n \mathrm{o}^{\prime}$ because all her vitamins she's getting ... right now is in her milk (T2)

She emphasized the importance of following directions:

Read the directions. I mean ... you've got to. That's the big thing, is you've got to do exactly [what the directions say]. Don't use too much water ... (T2)

She seemed well aware of overdilution potentially leading to "diarrhea" and infants "... not getting all their calorie intake ..." She also reported concerns about overconcentration, stating that formula prepared this way "... would be thicker ... If it's too thick they can choke" (T2). She repeated that her doctor advised her to add cereal to the bottle "... to thicken it up a little bit, to where she's not spitting her whole feeding up to cause her to lose weight" (T2). However, the doctor's recommendation was not fully embraced, because she also stated,

... I made one bottle [with full amount recommended by doctor] and ... it was really thick. I'm like, I'm not doing that. It's [2 tsp/ bottle, as demonstrated during observation] enough to where she's actually holding her feeding down ... that she's not spitting up and she's putting on the weight. So, that's all we care about ..." (T4)

When asked how mothers might decide solid food was a better option for an infant than another bottle of formula, she stated that this may be due to cost:

So they just don't have to [buy] formula. [It] is so expensive ... WIC only covers so many [canisters]. ... If you just get them onto the food you don't have to pay for the [additional] formula, [or for convenience] ... I think a lot of it is to fill them up so ... they'll sleep all night (T3)

Despite admitting to being worried initially about her ability to prepare formula properly, this experienced mother was well informed regarding proper reconstitution and was careful to attend to the appropriate ratio of water and powder. However, she did not express concern that the addition of cereal could disturb the intended composition. Although she took her doctor's advice seriously, she still modified the recommendation to suit the perceived needs of her infant (T4).

Vignette 2: Elizabeth, 30 years old, with a 1.5-month-old infant and 5 older children. Elizabeth appeared to reconstitute the formula properly and 
then added infant cereal. She recalled being "young," "nervous," and not wanting to "mess up" when first learning to prepare a bottle (T1). Elizabeth stated that an infant "... gets its nutrients and all that from the milk," and that she had "... never added more ... or less water ..." (T2). She explained that whereas formula may have provided adequate nutrition for her infant, it was "not enough" for her personally, in that she felt the need to add cereal to keep her infant fuller longer and so she could make fewer bottles. She stated, “... I don't do the cereal because [of] just the nutrients. I do the cereal because I think it makes them fuller ... it holds them over," and "... I go through less bottles putting cereal in my bottles than I do with no cereal, and they sleep way longer" (T3). Elizabeth later elaborated on this, stating she was

... not really saying that the can could last longer [by adding cereal] ... because, if your ... baby's greedy, it's just greedy. You know, different babies are different (T4)

She further conveyed that she understood this behavior was not recommended, but that this may not have pertained to her situation: "I've tried to go by the rules, and I've learned that 2 weeks, it's time for some cereal" (T4). This experienced mother believed that formula provided all of her infant's needs nutritionally, and did not appear concerned about how added cereal might change the nutrient distribution of bottle contents. She considered her intentional use of cereal to modify her infant's behavior to be an acceptable deviation from recommendations.

Vignette 3: Nicole, 38 years old, with a 2-month-old infant and 3 older children. Although she did not prepare a bottle with her own supplies, she did prepare a dilute unfamiliar bottle (8 oz water and 2 scoops of formula). She did not express a rationale for this over-dilution during the observation or interview. In fact, Nicole stated that formula was enough as long as "... they're gaining weight like they should" (T2), and expresses some understanding of how adding too much or too little water might affect an infant:

When extra water is added, they're not getting as much nutrients as they should. Like ... whatever vita- mins or whatever is in the formula ... They're getting more water... But then ... when there's too much formula, it supposed to cause constipation and, like, really bad gas... You probably just want to make it just like they ask you to.

However, she might not actually have understood the proper ratio, because she later stated, "... You're supposed to put 2 scoops per $8 \mathrm{oz}$, and then 1 scoop per $4 \mathrm{oz}^{\prime \prime}$ (T2). Formula prepared this way would be considered half-strength. Nicole also reported adding cereal to the bottle "... when they going to bed ..." to "... help them be more comfortable longer ... I have done that" (T3). She appeared to understand that some of her behaviors were not recommended, stating, "Oh goodness, I feel like I'm telling secrets" (T4). It is unclear how much cereal Nicole was adding, how frequently she may have been preparing over-dilute formula, and how this might have been affecting her infant. She reported learning to prepare formula using "trial and error," that early mistakes "... weakened [her] confidence," and that she did not ask for help because she "... didn't want to feel stupid" (T1).

Vignette 4: Naomi, 20 years old, with a 1-month-old infant. Naomi was observed preparing very over-dilute formula for both the typical and unfamiliar bottle ( 4 oz water and 1 scoop formula). However, statements made during the interview indicated that she may have been unaware she had prepared over-dilute formula; she stated that if extra water were added to formula "They can choke on it. It'll be too watery and the baby won't like it" (T2). Naomi went on to note that her infant "... whines a lot because she don't get full off of milk" (T3), which further indicated that she may have been over-diluting the formula. This first-time mother recalled being "confused" when learning to make formula (T1) and expressed concern about wasting formula, stating "... some people can't afford milk" (T3).

Vignette 5: Amber, 24 years old, with a 1-month-old infant. Amber appeared to use the correct water-toformula ratio for the typical bottle but over-diluted the unfamiliar bottle $(8 \mathrm{oz}$ water to 3 scoops formula). During both the observation and interview,
Amber reported intentionally, regularly over-diluting formula and provided a specific rationale for this behavior. She started by giving "... 2 scoops [to $8 \mathrm{oz}$ water] ... but she just didn't seem satisfied ..." (T2). Amber continued, stating

... I progress to ... 3 [scoops] and then ... I read the directions again and it said 4 [scoops]. ... But if she seemed like she was getting too much [determined by spitting up] ... I'll cut it down to ... either 3 and a half scoops or 3 scoops, depending on ... how she's throwing up that day. (T2)

She reported modifying the concentration to change her infant's sleep behaviors, stating:

... She would fall asleep and like, 5 minutes later she'd get right back up.... In my mind that means her stomach's not ... full enough so I started putting more [formula] scoops in it and she seemed fine. She would zonk out. (T3)

Amber explained why she added cereal:

I thought maybe she doesn't seem quite as satisfied with just the bottle, so I figured that the half the scoop of the cereal might thicken up just enough for her to be satisfied and probably, within like a month or so, it'll go up to a full scoop or a scoop and a half depending on how full she is. (T2)

She continued, explaining how she would eventually progress to only cereal in the bottle: If she's getting a full scoop I'd probably give her 3 scoops of the regular formula, just keep that there, and then give her a full scoop of the cereal and, as time goes on, the more cereal the less of the milk that I'd give her and eventually she'd just use all cereal. (T2)

This first-time mother noted being "pretty tense" and "very skittish" when making her first bottle (T1), but added: “... I didn't know how much you needed, but I didn't want to ask. ... So, basically, I just ... tried to stay quiet and do it myself ..." (T1).

\section{DISCUSSION}

Mothers in this study displayed a wide range of alignment between observed 
behaviors and verbalized attitudes and beliefs regarding the perceived adequacy of formula to meet infant needs, proper formula preparation, and potential modifications to prepared bottle contents. In addition, mothers in this sample indicated learning to prepare infant formula by observing others, reading formula container directions, or trial and error, and many reported feeling anxious about these early experiences. These findings are in alignment with those of Lakshman and colleagues, ${ }^{10}$ who reported the consistent theme of mothers not communicating their lack of knowledge to their health care providers. However, Lakshman and colleagues suggested that this may be explained by mothers believing they already knew how to prepare formula properly and did not need to request education. Mothers in the current study were not queried directly about why they did or did not discuss formula preparation with a health care provider. However, some statements, such as those made by the women called Nicole and Amber in this article, revealed concerns that their anxiety and lack of understanding of how to prepare formula properly may have been undesirable to communicate to health care providers for fear of being made to feel unintelligent. This adds to the growing body of literature indicating that mothers who formula-feed, regardless of whether they also partially breastfeed, may believe that their chosen mode of feeding will be frowned upon, and therefore they may be hesitant to enter into a discussion with their health care provider. $^{10,18,20,21}$ Despite their early doubts, mothers reported gaining confidence over time and becoming comfortable with formula preparation. In fact, many mothers had no concerns with modifying formula by adding infant cereal if they perceived that its addition would extend infant sleep or fullness, or result in the preparation of fewer bottles. These qualitative findings are supported by previous literature indicating that adding cereal to bottles is potentially motivated by maternal convenience and financial concerns. $^{18,20,21}$ Importantly, because WIC is supplemental, caregivers are responsible for purchasing formula after their monthly supply is depleted. ${ }^{22}$ According to Oliveira and colleagues, ${ }^{6}$ depending on the volume of infant intake, it is estimated the monthly formula allotment for exclusively formulafeeding infants should provide all necessary nutrients until around age 3 months, at which point additional formula will need to be purchased. A study by Fornasaro-Donahue and colleagues $^{21}$ exploring how the cost of formula may influence the choice to breastfeed among pregnant WIC participants estimated this additional cost to be about $\$ 46 /$ month by age 4 months. Regardless of planned feeding mode, the researchers found that these mothers had little idea how much additional formula would cost. This is of concern, because formula is more expensive than both infant cereal and typical solid foods marketed for infants, and supplementing and/or replacing formula feeds with these alternatives may seem to be the most logical and affordable option for low-income populations. ${ }^{21}$ If mothers are unaware of the potential long-term consequences of improper infant-feeding behaviors, or if the recommended practices are considered incongruent with real-world needs, the perceived convenience and costeffectiveness of these behaviors will likely weigh more heavily in the decision-making process. ${ }^{18}$

Results of this study indicated that bottle-preparation behaviors that are outside infant feeding recommendations occurred among low-income, formula-feeding mothers of young infants in the Southeastern US. Regardless of intent, mothers often contradicted themselves when describing their attitudes and beliefs toward bottle preparation, because observed behaviors often differed from those reported in the interviews. Therefore, it should not be assumed that reported behaviors are always congruent with actual behaviors and that relying only on maternal report of bottle preparation behaviors may result in collection of incomplete data and missed education opportunities. The experiences of these mothers add to the ongoing conversation regarding appropriate and sensitive dissemination of infant-feeding messages, because health care providers must balance providing strong support for breastfeeding with providing formula feeding guidance to those who decide, or are compelled, to use it. ${ }^{23}$

An important strength of this study was the combination of qualitative de- scriptions of maternal bottle-preparation practices and observational data collected during the same visit. The home observations provided a limited quantitative description of formula preparation, whereas the interviews resulted in rich textual data explaining some of the observed maternal behaviors and alluding to some that were not observed. Collecting both quantitative and qualitative data during the same data collection point, and systematically integrating these data together, can provide more complete results than those obtained by individual methods alone. ${ }^{24,25}$ A common reason for using such an approach is to triangulate or validate data by testing the same research question using more than 1 methodology, to see whether different methodologies provide the same or similar results. ${ }^{24}$ For example, in the current study, improper formula preparation behaviors were not only observed by researchers but also described by these mothers, which further validated the finding that these behaviors are prevalent among the study population.

The cross-sectional study design is a limitation of this study, because behaviors of interest may have occurred before or after each home visit, but were not demonstrated during the actual observation. A longitudinal study using more intensive observational methodology may capture a greater variety of behaviors. It is also possible that the observations and reported behaviors were influenced by the mothers' desire to report or practice socially acceptable behaviors, which could vary from their normal behaviors. Future research should employ novel methodologies to assist in reducing this bias. Finally, although the researchers reached saturation in the indepth interviews, it is not possible to generalize results from this type of study design to broader populations. Results presented here are likely to apply to a limited group of low-income, predominantly formula-feeding, single women in the Southeastern US. Future research should explore these questions among groups likely to have access to greater resources, such as mothers of higher income, those who are married or cohabitating, and/or those with full-time employment. In addition, exploring these questions among other types of caregivers could 
assist with understanding formula preparation practices affecting a large population.

\section{IMPLICATIONS FOR RESEARCH AND PRACTICE}

Health care providers and others who work with mothers of infants should not assume that infant formula is being prepared consistently according to recommendations. Although breastfeeding is recognized as the reference standard in infant feeding, support for breastfeeding must be delicately balanced with support for mothers who choose to, or must, provide infant formula. Targeting gaps in knowledge and skills related to proper formula preparation, along with the motivators of maternal behavior described in this study and others, will be essential to diminishing the prevalence of maternal infant-feeding practices that differ from recommendations among this target population. Ultimately, supporting proper infant formula preparation may lead to positive short-term and long-term health outcomes for formula-fed infants in the US, thereby decreasing associated national health care expenditures. Further research is needed to understand better maternal infant formula preparation behaviors that differ from recommendations, especially among low-income, formula-feeding mothers in the Southeastern US.

\section{ACKNOWLEDGMENTS}

This study was funded by the US Department of Agriculture (National Institute of Food and Agriculture, Agriculture and Food Research Initiative grant 2010-85215-20663). The authors wish to extend thanks to the mothers who graciously allowed them into their homes and for the assistance of graduate research assistants Jennifer Waller, Angela Sberna, and Courtney Wright.

\section{REFERENCES}

1. National Center for Chronic Disease Prevention and Health Promotion. Breastfeeding Report Card: Progressing Toward National Breastfeeding Goals - United States, 2016. Atlanta, GA: Division of Nutrition, Physical Activity, and Obesity; 2016.
2. Gibbs BG, Forste R. Socioeconomic status, infant feeding practices and early childhood obesity. Pediatr Obes. 2014;9:135-146.

3. Ryan AS, Zhou W, Gaston MH. Regional and sociodemographic variation of breastfeeding in the United States, 2002. Clin Pediatr. 2004;43:815-824.

4. Siega-Riz AM, Deming DM, Reidy KC, Fox MK, Condon E, Briefel RR. Food consumption patterns of infants and toddlers: where are we now? J Am Diet Assoc. 2010;110:S38-S51.

5. Jones KM, Power ML, Queenan JT, Schulkin J. Racial and ethnic disparities in breastfeeding. Breastfeed Med. 2015; 10:186-196.

6. Oliveira V, Racine E, Olmsted J, Ghelfi LM. The WIC program: background, trends, and issues. Food Assistance and Nutrition Research Report No. 27. Food and Rural Economics Division, Economic Research Service, US Department of Agriculture; 2002. https://www.ers. usda.gov/webdocs/publications/46648/ 15831_fanrr27fm_1_.pdf?v=41063. Accessed October 7, 2016.

7. May L, Borger C, Weinfield N, et al. WIC Infant and Toddler Feeding Practices Study-2: Infant Year Report. Rockville, MD: Westat; 2017.

8. Oliveira V, Frazão E, Smallwood D. Rising infant formula costs to the WIC Program: recent trends in rebates and wholesale prices. Economic Research Report No. 93. Economic Research Service, US Department of Agriculture; 2010. https://www.ers.usda.gov/publications/ pub-details/?pubid $=46371$. Accessed January 28, 2017.

9. Renfrew MJ, Ansell P, MacLeod KL. Formula feed preparation: helping reduce the risks: a systematic review. Arch Dis Child. 2003;88:855-858.

10. Lakshman R, Ogilvie D, Ong KK. Mothers' experiences of bottlefeeding: a systematic review of qualitative and quantitative studies. Arch Dis Child. 2009;94:596-601.

11. Fein SB, Falci CD. Infant formula preparation, handling, and related practices in the United States. J Am Diet Assoc. 1999;99:1234-1240.

12. Daly A, MacDonald A, Booth IW Diet and disadvantage: observations on infant feeding from an inner city. J Hum Nutr Diet. 1998;11:381-389.

13. American Academy of Pediatrics Committee on Nutrition. Feeding the infant. In: Kleinman RE, Greer FR, eds. Pediatric Nutrition. $7^{\text {th }}$ ed. Elk Grove Village,
IL: American Acadamy of Pediatrics; 2014.

14. Burkhardt MC, Beck AF, Kahn RS, Klein MD. Are our babies hungry? Food insecurity among infants in urban clinics. Clin Pediatr. 2012;51:238-243.

15. Gross RS, Mendelsohn AL, Fierman AH, Hauser NR, Messito MJ. Maternal infant feeding behaviors and disparities in early child obesity. Child Obes. 2014;10:145-152.

16. Gross RS, Mendelsohn AL, Fierman AH, Racine AD, Messito MJ. Food insecurity and obesogenic maternal infant feeding styles and practices in low-income families. Pediatrics. 2012;130:254-261.

17. WIC income eligibility guidelines. http:// www.fns.usda.gov/wic/wic-incomeeligibility-guidelines-2012-2013. Accessed October 7, 2016.

18. Heinig MJ, Follett JR, Ishii KD, Kavanagh-Prochaska K, Cohen R, Panchula J. Barriers to compliance with infant-feeding recommendations among low-income women. J Hum Lact. 2006;22:27-38.

19. Clarke V, Braun V. Thematic analysis. In: Teo T, ed. Encyclopedia of Critical Psychology. New York, NY: Springer; 2014:1947-1952.

20. Waller J, Bower KM, Spence M, Kavanagh KF. Using grounded theory methodology to conceptualize the mother-infant communication dynamic: potential application to compliance with infant feeding recommendations. Matern Child Nutr. 2015;11:749-760.

21. Fornasaro-Donahue VM, Tovar A, Sebelia L, Greene GW. Increasing breastfeeding in WIC participants: cost of formula as a motivator. J Nutr Educ Behav. 2014;46:560-569.

22. WIC Food Packages: maximum monthy allowances. http://www.fns.usda.gov/wic/ wic-food-packages-maximum-monthlyallowances. Accessed October 7, 2016.

23. Dykes F, Richardson-Foster H, Crossland N, Thomson G. "Dancing on a thin line": evaluation of an infant feeding information team to implement the WHO code of marketing of breast-milk substitutes. Midwifery. 2012;28:765-771.

24. Creswell JW, Klassen AC, Plano Clark VL, Smith KC. Best Practices for Mixed Methods Research in the Health Sciences. Bethesda, MD: National Institutes of Health, Office of Behavioral and Social Sciences Research; 2011:10-37.

25. Yin RK. Mixed methods research: are the methods genuinely integrated or merely parallel? Res Sch. 2006;13:41-47. 


\section{CONFLICT OF INTEREST}

The authors have not stated any conflicts of interest. 